\title{
Changes in levels of morbidity and hospitalisation in Kerala: A district level analysis (1995-2014)
}

\author{
Kalosona Paul*, Mamta Chaudhary, Ravindra Chowdhary, Rituparna Sengupta \\ School of Development Studies, Tata Institute of Social Sciences, Opp. Deonar Bus Depot, V.N. Purav Marg, Mumbai, 400088, Maharashtra, India
}

\section{A R T I C L E I N F O}

\section{Keywords:}

Morbidity

Types of morbidity

Multivariate technique

Hospitalization

District

Kerala

\begin{abstract}
A B S T R A C T
Background: The objective of paper is to provide background information about the morbidity and hospitalization pattern in districts Kerala based on secondary data.

Methods: Using data from three rounds (52nd, 60th, and 71st) of National Sample Survey Organization (NSSO), the trend and pattern of self-reported morbidity were analysed across districts of Kerala. Descriptive analysis was carried out to understand the prevalence of self-reported morbidity variation over a period of two decades (1995-2014) and multivariate analysis was performed to identify the significant determinants of various types of self-reported morbidities and hospitalization.

Results: The results indicate that while infectious diseases and NCDs increased by six times, CVDs increased by nearly nine times, and disability increased by five times from 1995 to 2014 . Age, sex and location emerged as significant determinant of morbidity, with the elderly, female and urban areas depicting higher levels. Levels of morbidity and hospitalization were higher in the Southern part of Kerala than in Northern Kerala.

Conclusions: The emerging pattern of high morbidity in Kerala warrants treatment and constant medical attention in primary and community level, especially among elderly person. There is a need for widened and sustained public health care system with affordable average cost of treatment for NCDs and CVDs at the primary level.
\end{abstract}

\section{Introduction}

The southern state of Kerala, with a per capita income less than many of the other states in India, sets a finest example that economic measures cannot limit attainments in social indicators. Ranking first in human development index in India, Kerala has a low-cost healthcare system, high life expectancy, low infant mortality and low birth rate which is at par with the developed world ${ }^{1,}$ thereby earning the status of "state with good health". Despite Kerala being highly praised for its health care, which is based on the estimates of mortality indicators, the real situation is strikingly different. The low overall mortality coexists with extensive morbidity, and according to National-level surveys, Kerala records the highest morbidity than elsewhere in India. ${ }^{2-4}$ Mortality in Kerala is only half that of Indian average which is a result of availability of medical care in the remotest village, usages of facilities by the population and the wide inclusion of vaccinations among infants and children.

Although Kerala has made remarkable accomplishments in sociodemographic indices, the high level of morbidity initiated discussion on the 'low mortality and high morbidity syndrome' in Kerala. The vast majority of these studies depend upon reported morbidity or on perceived morbidity, which, to great extent, relies upon a person's view of illness. ${ }^{5}$ Kerala has extended health service, combined with universal literacy as compared to the past and this might be a reason for early detection and diagnosis of diseases and results in the high morbidity rates in Kerala. ${ }^{6-10}$ However, every one of these discussion concluded that high reported morbidity isn't because of perception factors; ${ }^{11}$ and higher morbidity in Kerala is a genuine burden of morbidity within the Kerala population. ${ }^{7,12}$

Development in Kerala is not uniform across geographical space and socio-economic groups. Morbidities are 40 percent more likely among poor people than that of the rich people. ${ }^{9}$ Kerala has gone under epidemiological polarization, wherein mortality is low and morbidity is very high. ${ }^{8}$ Non-communicable diseases are more prominent in Kerala; with infectious diseases and malnutrition being concentrated among the poor and lifestyle diseases are on the rise among the rich. ${ }^{6,14}$

Measures of self-reported morbidity have an immediate relation with the wellbeing of any given population and therefore the morbidity pattern of a population is considered as a proxy measure for comprehending their health status. ${ }^{8,11,14}$ However, no recent studies have

\footnotetext{
* Corresponding author.

E-mail addresses: kalosonapaul@gmail.com (K. Paul), chaudharymamta092@gmail.com (M. Chaudhary), chowdhary1191@gmail.com (R. Chowdhary).
} 
explored the pattern of morbidity and hospitalization in Kerala using large-scale survey data. The present paper focuses on the trend, level and patterns of the morbidity transition and hospitalization issues in Kerala using the three rounds of morbidity round of NSSO data. The study simultaneously captures the scenario of Infectious, CVDs, NCDs, disability and the other main types of ICD based on 2010 disease category.

\section{Materials and methods}

In this study, we are using three round of National sample survey organization (NSSO) to explore the burden of morbidity. The individual cases of 24304 (Rural: 13990 and Urban: 10314) 13403 (Rural: 8683 and Urban: 4720), and 11229 (Rural: 5484 and Urban: 5745) were incorporated in the 52nd, 60th and 71st rounds respectively (Appendix 1 ). In the 52nd rounds of NSSO, information was gathered on 58 different morbidity symptoms, in 60th round it was reduced to 42 different types of morbidities, and in the recent round of 71st NSSO data was collected 61 diverse of nature of ailments for fixed reference periods of 15 days. All the three rounds of data collecting the nature of ailments have the same reference period of the last 15 days prior to the survey date. Self-reported morbidities were classified into five broad categories: infectious diseases, cardiovascular diseases (CVDs), noncommunicable diseases (NCDs), disability and other diseases. The classification of diseases is based on the International Classification of Disease (Appendix 2). ${ }^{30}$

The analysis has been carried out using three simple statistical tools. To compute the prevalence of morbidity per thousand population, following formula was used:

$\boldsymbol{P i}=\frac{\boldsymbol{M i}}{\boldsymbol{T i}} *$ thousand

Where,

$\mathrm{Mi}=$ Number of persons with a particular ailment

$\mathrm{Ti}=$ Total number of persons alive in the sample households.

The morbidity variable was a dichotomous variable (yes/no). We carried out bivariate analysis between the background characteristics and the outcome variable i.e. morbidities such as infectious disease, CVDs, NCDs, disability and other diseases. Background characteristics considered in the study are sex, place of residence, age, level of education, social group, caste, religion, monthly per capita consumer expenditure (MPCE). The multivariate analysis was performed in this study;

$\operatorname{Logit}(\mathrm{Y})=\ln \left(\frac{\boldsymbol{p}}{1-\boldsymbol{p}}\right)=\alpha+\beta_{1} \boldsymbol{x}_{1}+\beta_{2} \boldsymbol{x}_{2}+\epsilon$

Where, $p$ is the probability of the event and $\alpha$ is intercept, $\beta$ s are regression coefficients, $x i$ is set of predictors and $\epsilon$ is an error term.

\section{Results}

\subsection{Trends in self-reported morbidity in Kerala}

In Kerala, the morbidity prevalence rate reached from 110 to 308 per thousand population within two decades i.e. 1995-2014 (Fig. 1). Out of five types of diseases, infectious diseases approximately increased by six times, CVDs nearly by nine times, NCDs by nearly six times, and disability increased by five times from 1995 to 2014 (Fig. 2).

Among the major districts in Kerala, Kottayam district reported a drastic increase in the prevalence of infectious diseases in the two decades - from 9 per thousand population to 31 per thousand population in the first decade 1995-2004 and from 31 per thousand population to 110 per thousand population in the second decade 2004-14. In the last decade, Thiruvananthapuram reported almost no change in the prevalence of infectious diseases. Also, the maximum prevalence of infectious diseases was reported by Kottayam and minimum was found in Pathanamthitta district in the year 2014. Over the period, self-reported CVDs was highest in Kottayam, recording an astounding 159 per thousand population from 59 per thousand population within a period of two decades. Furthermore, in 2014 the highest prevalence of CVDs was reported by Kottayam, followed by Thrissur and Thiruvananthapuram. Overall, CVDs in Kerala increased from 2 to 15 per thousand population in the last two decades. In Kerala, the highest increase in morbidity prevalence was noticed in NCDs, from 18 per thousand population to 109 per thousand population from 1995 to 2014 (Table 1). Thrissur district reported maximum and Pathanamthitta reported the minimum prevalence of NCDs in 2014. In Alappuzha, the highest increase was 50 per thousand population to 158 per thousand population in 2004 and 2014 respectively. In Wayanad, there was no change in the last two decades of NSS. In Kottayam, the highest increase in disability was seen from 58 per thousand population to 121 per thousand population in 2004 and 2014 respectively. Secondly, the highest increase was seen in Thiruvananthapuram from 59 per thousand populations to 112 per thousand population in 2004 and 2014 respectively. Ernakulam recorded a decreasing trend, from 51 per thousand population to 49 per thousand population and in Pathanamthitta from 54 per thousand population and 31 per thousand population in 2004 and 2014 respectively (Fig. 3).

Table 2 gives an outline of self-reported morbidity by selected background characteristics. Infectious disease was slightly higher in rural areas during the first two rounds of NSS, but marginally increased among the urban residents in the last round of NSS. It was also found to be consistently higher among the male population. In the first two rounds of NSS, disability was higher among rural residents and in the last round of NSS, it was found higher among the urban residents. NCDs were slightly higher among the rural population in the first round of NSS and increased in the urban population in the last two rounds of NSS. CVDs and disability among the female population were consistently higher than their male counterparts in all the three rounds of NSS. NCDs were higher in the female population in the first and last round of NSS but were higher in the male population compared to the female population by a point in the second round of NSS. Infectious disease and CVDs decreased as the level of education increased in first and last rounds of NSS but increased slightly in the graduate and above years as compared to higher secondary education.

Prevalence of CVDs and disability increases as we move up the ladder of age group. CVDs were found to be higher among poorest and richest income quintile and lower among the middle-income quintile. Furthermore, among Christians prevalence of infectious diseases, CVDs, and NCDs, and other kinds of morbidity was higher than Hindus and Muslims. Currently married women have a higher risk of CVDs, NCDs, and disability than never-married women in all the rounds of NSS. CVDs were higher in the poorest and richest quintile and lower in the medium wealth quintile. In addition, in the last two rounds of data NCDs was higher in the poorest and richest wealth quintiles as compared to medium wealth quintile (Table 2).

\subsection{Multivariate analysis}

The results of logistic regression are presented in Table 3. Females were less likely to report self-reported infectious diseases compared to males, in the first round of NSS (OR: 0.643, p < 0.05). Whereas, urban (OR: $0.72, \mathrm{p}<0.05$ ) people were less significant as compared with the reference group of rural areas in 2004. Similarly, in the first round of NSS, those with Illiterates, graduate and above were more likely to have an infectious disease as compared others education group. Though the trend of infectious morbidity among primary education groups are increasing in nature, graduates \& above portray a decreasing nature. Similarly, Less than 15 groups of peoples are having more significance in 


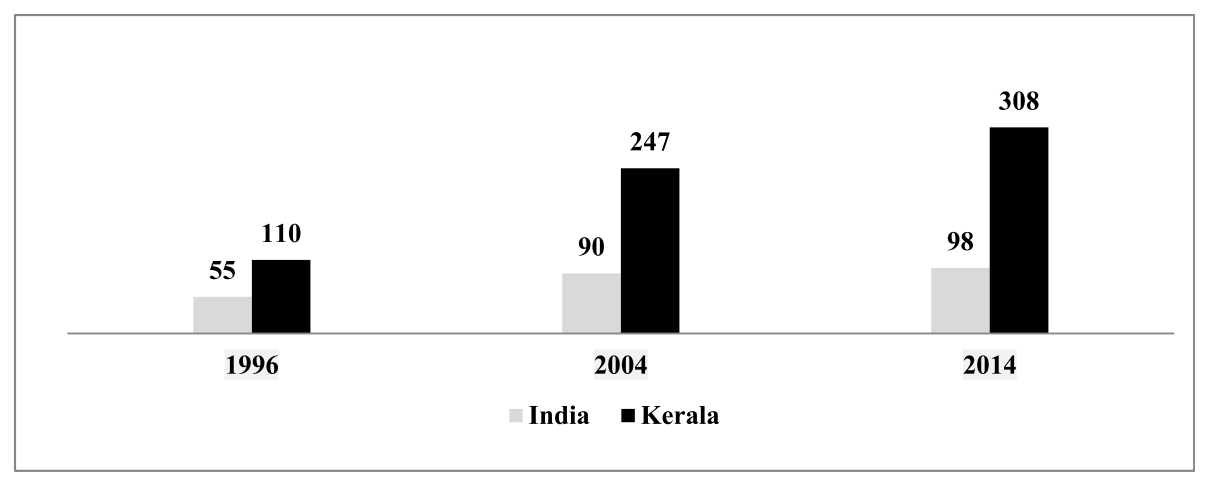

Fig. 1. Self reported morbidity prevalence (Per thousand) among Kerala and India, 1995-2014.

all rounds. In the last round of NSS, NCDs are more likely to be reported among females (OR: 1.362, p < 0.01) as compared to males. In the third round of NSS, NCDs are more likely to be reported among urban residents (OR: 1.143, p < 0.05) as compared to rural residents. Interestingly, NCDs was more significantly increase among all age groups from 1995 to 2014. Also, in the last round of NSS, rich (OR: 1.554, $\mathrm{p}<0.05$ ) and richest (OR: 1.737, $\mathrm{p}<0.05$ ) group are more likely of having NCDs as compared to poorest income group. In addition, in the first round of NSS, other kinds of disease are more likely among the rich and richest group as compared to the poorest group. With an increase of family members was a negative association with infectious diseases over all rounds. Almost in all the rounds of NSS, the southern region is more likely of having all kinds of morbidity as compared to the northern region. Overall, in the first round of NSS, self-reported morbidity was significantly less likely among females, the population with a higher level of education, nodal families and in the southern region as compared to others. And, NCDs was significantly more likely among all education groups, elderly, and richest quintile households in all three rounds.

\subsection{Hospitalization cases}

In the rural population, hospitalized cases due to infectious diseases reported highest among 0-14 age groups (0-4: 47.4\% \& 5-14: 32\%). Among the Infectious Diseases, the percentage of Diarrhea/Dysentery $(34.1 \%)$ is highest in rural areas among 0-4 age group whereas Gastric and Peptic ulcers accounted for the significant proportion of hospitalized cases increasing age group 5-14 (9.2\%) and 60+ (11.8\%). Also, the hospitalized cases due to CVDs in rural population reported highest in the age group are $60+(26.2 \%)$. The largest proportion of hospitalized cases contributed due to heart disease reported as $11.2 \%$ in the 45-59 age group and $14.4 \%$ in $60+$. Age group wise hospitalized cases due to NCDs were highest among the age groups $45-59$ and $60+$ were
$36.3 \%$ and $25 \%$ respectively. In the rural population, under NCDs, $30.4 \%$ hospitalized cases were due to cataract among $0-4$ age group whereas $9.3 \%$ and $11.5 \%$ reported cases were due to bronchial asthma among 5-14 and $60+$ age groups respectively. The hospitalized cases reported due to Cancer (5.2\%), and Cataract (10.4) is highest among 60 and above age group. The percentage of hospitalized cases due to the Disability as a type of ailment reported $21.5 \%$ among 5-14, $22.3 \%$ among $30-44,21.9 \%$ among $45-59$ and $13.5 \%$ among $60+$. The hospitalized cases due to mental disorder reported among the working group of $30-44$ were $11.1 \%$, however, accidental injury, road traffic and falls reported in the mobile population was $14.4 \%$ under fourteen ages whereas working age groups is $22.2 \%$. In "Others" ailment category, $8.2 \%$ and $9.8 \%$ of hospitalized cases were due to All other fevers (includes malaria, typhoid) among $0-4$ and $5-15$ age group respectively (Table 4).

\section{Discussion}

In the course of the most recent two decades, the majority of Selfreported morbidities have been on the rise in Kerala (1995-2014). The factors such as caste, customs, economic status, media exposure, and levels of educational attainment add to self-reported bias. ${ }^{8}$ A higher prevalence of NCDs, CVDs, and infectious disease may also be partly because of the presence of a larger percentage of old age population in Kerala. ${ }^{15,16}$ The diminishing pattern of another type of morbidities may be a result of progress in the grouping of morbidities in the continuous round in light of the fact that, less number of morbidities was incorporated into other morbidity classification in the ongoing round when contrasted with the past rounds of NSS. Also, there is an increasing trend in infectious diseases in both rural and urban areas, signaling a serious worry for better sanitation, awareness and healthcare provisions. Similarly, the rise of CVDs and NCDs in urban areas is disturbing, ${ }^{17}$ almost certainly, the urban communities will be more

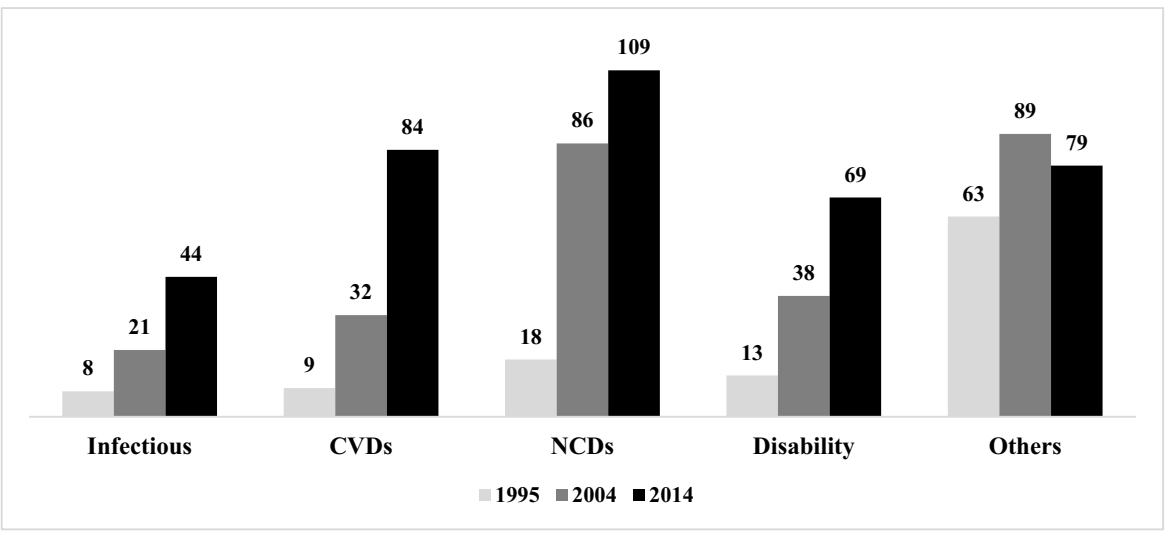

Fig. 2. Prevalence of various types self-reported morbidity (Per Thousand) in Kerala, 1995-2014. 
Table 1

Prevalence of different type of self-reported morbidity in Kerala, 1995-2014 (Per thousand populations).

\begin{tabular}{|c|c|c|c|c|c|c|c|c|c|c|c|c|c|c|c|}
\hline \multirow[t]{2}{*}{ Districts/States/India } & \multicolumn{3}{|l|}{ Infectious } & \multicolumn{3}{|l|}{ CVDs } & \multicolumn{3}{|l|}{ NCDs } & \multicolumn{3}{|l|}{ Disability } & \multicolumn{3}{|l|}{ Others } \\
\hline & 1995-96 & 2004 & 2014 & 1995-96 & 2004 & 2014 & 1995-96 & 2004 & 2014 & 1995-96 & 2004 & 2014 & 1995-96 & 2004 & 2014 \\
\hline Kasaragod & 1 & 13 & 50 & 2 & 14 & 31 & 12 & 31 & 59 & 6 & 18 & 56 & 16 & 59 & 67 \\
\hline Kannur & 6 & 9 & 10 & 1 & 24 & 61 & 5 & 52 & 73 & 12 & 16 & 39 & 20 & 50 & 65 \\
\hline Wayanad & 13 & 22 & 38 & 3 & 27 & 50 & 9 & 87 & 87 & 7 & 40 & 56 & 53 & 104 & 38 \\
\hline Kozhikode & 6 & 7 & 42 & 2 & 31 & 69 & 13 & 67 & 68 & 14 & 32 & 73 & 55 & 78 & 76 \\
\hline Malappuram & 6 & 16 & 49 & 7 & 16 & 67 & 15 & 47 & 65 & 10 & 18 & 48 & 41 & 100 & 69 \\
\hline Palakkad & 14 & 10 & 37 & 5 & 17 & 21 & 13 & 35 & 95 & 12 & 23 & 55 & 92 & 52 & 56 \\
\hline Thrissur & 2 & 32 & 69 & 3 & 44 & 134 & 5 & 142 & 182 & 8 & 56 & 99 & 32 & 155 & 77 \\
\hline Ernakulam & 9 & 23 & 66 & 10 & 43 & 102 & 20 & 125 & 154 & 10 & 51 & 49 & 70 & 83 & 116 \\
\hline Idukki & 8 & 55 & 27 & 7 & 45 & 32 & 26 & 62 & 43 & 21 & 72 & 109 & 115 & 132 & 67 \\
\hline Kottayam & 9 & 31 & 110 & 15 & 50 & 159 & 35 & 113 & 149 & 17 & 58 & 121 & 141 & 128 & 129 \\
\hline Alappuzha & 5 & 16 & 8 & 18 & 7 & 83 & 21 & 50 & 158 & 13 & 25 & 27 & 73 & 70 & 61 \\
\hline Pathanamthitta & 5 & 15 & 3 & 17 & 40 & 35 & 24 & 60 & 42 & 15 & 54 & 31 & 56 & 74 & 26 \\
\hline Kollam & 20 & 6 & 32 & 24 & 20 & 104 & 32 & 44 & 125 & 17 & 15 & 74 & 100 & 97 & 92 \\
\hline Thiruvananthapuram & 13 & 45 & 44 & 14 & 54 & 115 & 25 & 181 & 131 & 16 & 59 & 112 & 37 & 65 & 92 \\
\hline KERALA & 8 & 21 & 44 & 9 & 32 & 84 & 18 & 86 & 109 & 13 & 38 & 69 & 63 & 89 & 79 \\
\hline INDIA & 8 & 17 & 25 & 2 & 7 & 15 & 8 & 22 & 24 & 6 & 13 & 20 & 32 & 34 & 22 \\
\hline
\end{tabular}

Sources: NSSO Data, 52nd, $60^{\text {th }} \& 71$ st round.

vulnerable to both diseases. ${ }^{20,23}$ Recent examination shows that hypertension was significantly higher among urban females when compared to rural females. ${ }^{18,19}$

Studies suggest that accessibility to health services, health ideals, nutritional status, domestic violence, education levels, socioeconomic status, lifestyle of the population are mostly the explanations for variations in self-reported morbidity. ${ }^{11,16,20,21}$ The people of higher-economic status and educated elderly might be more mindful of medical problems and accordingly be generally less inclined to underreport minor medical issues or intense sicknesses than their counterparts in a poorer economic situation. ${ }^{5,22,28}$ Also the lifestyle-related nature of chronic conditions may have added to the higher prevalence of chronic ailments, resulting in a higher burden of morbidity and hospitalization among the better-off subgroups. As demonstrated by the Census of India 2011, Kerala records the highest levels of literacy (95\%), in India. ${ }^{29}$ It is most likely that people in Kerala are more worried about their normal wellbeing checkups so that is why morbidity reporting is higher in Kerala. Consequently, high educational status, despite the fact that it enhances self-reported morbidity, may not really increase the prevalence of morbidity. Also, the population of various areas in Kerala is experiencing diverse dimensions of demographic and epidemiological transition so this could be an explanation behind variation in self-reported disease profile of the populations emerging from different areas. $^{25,26,37}$ Reporting of CVDs and NCDs were still higher in south urban Kerala whereas rural areas largely affected due to infectious diseases like diarrhea. Also, the reporting of inpatient hospitalization cases were higher in the southern region than northern Kerala whereas northern rural regions are attribution of infectious and disability problems. Economically well-off people and returned emigrants are more likely to suffer multiple diseases of CVDs and NCDs than poor and nonmigrants families. ${ }^{26}$ In addition, the high elderly population has created $\mathrm{J}$-shaped association with level of morbidity and hospitalization. ${ }^{11}$ At
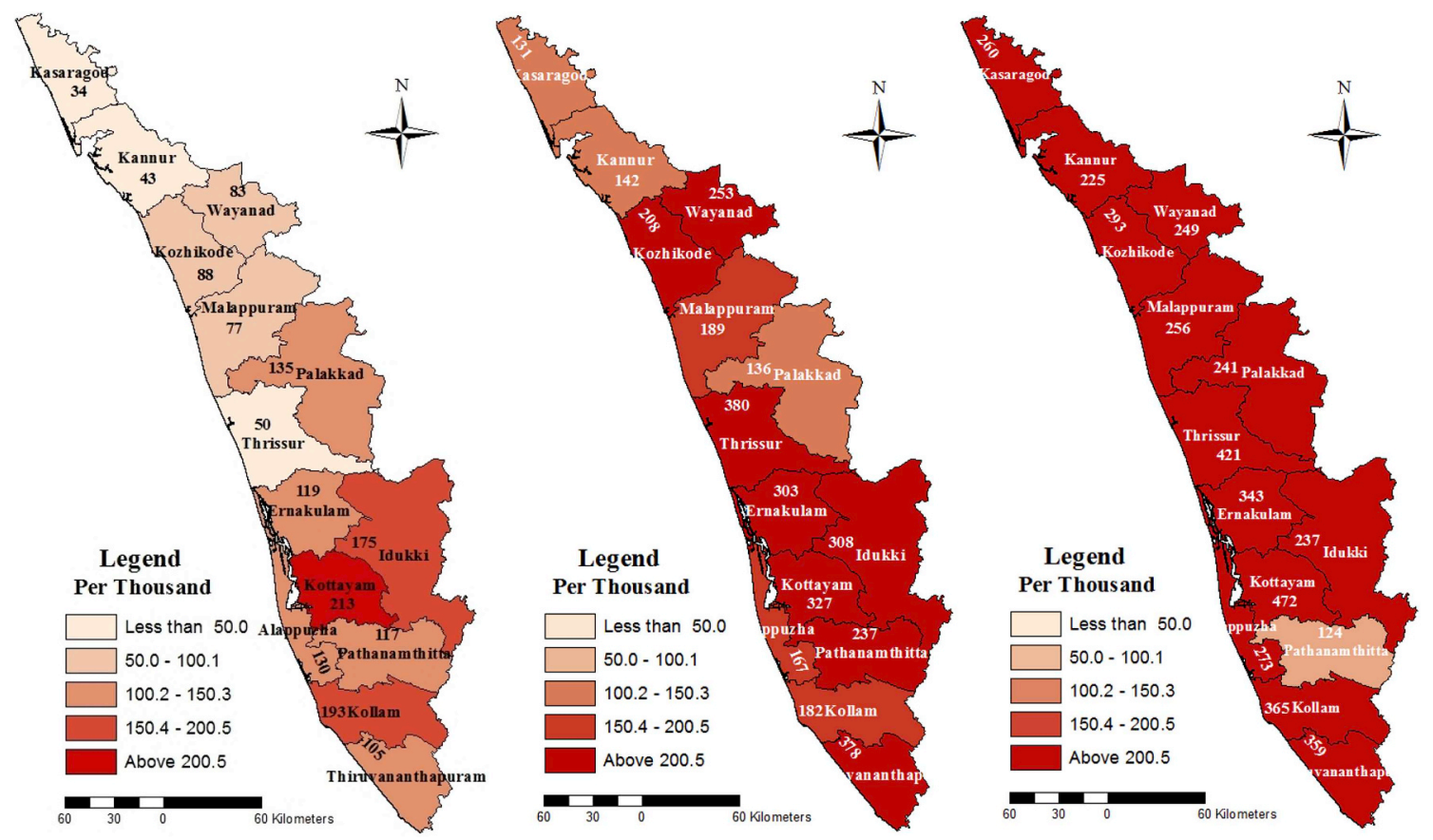

Fig. 3. District wise Self reported morbidity in Kerala, 1995-2014. 
Table 2

Prevalence of ailments by background characteristics in Kerala, 1995-2014 (Per thousand populations).

\begin{tabular}{|c|c|c|c|c|c|c|c|c|c|c|c|c|c|c|c|}
\hline \multirow[t]{2}{*}{ Background Characteristics } & \multicolumn{3}{|c|}{ Infectious } & \multicolumn{3}{|c|}{ CVD } & \multicolumn{3}{|c|}{ NCD } & \multicolumn{3}{|c|}{ Disability } & \multicolumn{3}{|c|}{ Others } \\
\hline & 1995 & 2004 & 2014 & 1995 & 2004 & 2014 & 1995 & 2004 & 2014 & 1995 & 2004 & 2014 & 1995 & 2004 & 2014 \\
\hline \multicolumn{16}{|l|}{ Sex } \\
\hline male & 9.9 & 21.4 & 45.0 & 8.6 & 29.1 & 83.3 & 16.6 & 86.8 & 92.8 & 11.8 & 30.4 & 57.5 & 63.2 & 84.6 & 81.9 \\
\hline female & 7.0 & 21.2 & 43.4 & 9.6 & 34.4 & 84.0 & 19.4 & 85.1 & 124.6 & 13.6 & 44.0 & 80.2 & 62.6 & 92.9 & 75.3 \\
\hline \multicolumn{16}{|l|}{ Place of Residence } \\
\hline rural & 8.7 & 23.0 & 43.0 & 9.7 & 30.0 & 84.3 & 19.4 & 85.4 & 106.3 & 14.1 & 39.2 & 67.8 & 66.8 & 91.6 & 79.0 \\
\hline Urban & 7.4 & 16.5 & 45.6 & 7.2 & 37.0 & 83.0 & 13.9 & 87.5 & 113.2 & 8.4 & 32.7 & 71.1 & 50.9 & 81.6 & 77.8 \\
\hline \multicolumn{16}{|l|}{ Education } \\
\hline Illiterate & 15.6 & 39.6 & 74.8 & 12.6 & 40.4 & 83.9 & 25.5 & 112.5 & 99.1 & 18.2 & 52.0 & 65.7 & 85.2 & 131.0 & 129.9 \\
\hline Primary & 8.7 & 24.6 & 50.4 & 10.1 & 44.1 & 122.9 & 21.4 & 99.1 & 126.8 & 14.0 & 47.9 & 87.9 & 65.1 & 103.0 & 76.6 \\
\hline Higher Secondary & 5.5 & 13.3 & 35.3 & 6.9 & 21.4 & 67.7 & 12.5 & 72.7 & 106.4 & 9.7 & 28.2 & 65.7 & 54.0 & 71.0 & 69.0 \\
\hline graduate $\&$ above & 4.4 & 18.3 & 30.0 & 8.3 & 29.2 & 46.5 & 13.8 & 52.8 & 84.9 & 9.7 & 19.6 & 34.6 & 45.0 & 47.0 & 64.0 \\
\hline \multicolumn{16}{|l|}{ Age Group } \\
\hline$<15$ & 9.9 & 22.2 & 57.1 & 1.8 & 0.0 & 1.6 & 10.6 & 63.7 & 22.4 & 7.4 & 8.2 & 16.9 & 87.9 & 112.9 & 101.5 \\
\hline $15-34$ & 4.3 & 12.7 & 23.2 & 2.2 & 2.9 & 7.3 & 10.0 & 42.1 & 31.0 & 7.2 & 18.8 & 29.1 & 42.2 & 62.6 & 48.4 \\
\hline $35-59$ & 8.2 & 22.3 & 46.2 & 12.5 & 40.3 & 94.5 & 21.0 & 100.0 & 159.8 & 16.3 & 46.8 & 94.2 & 62.9 & 92.2 & 82.7 \\
\hline $60+$ & 20.2 & 42.8 & 62.2 & 46.7 & 167.0 & 323.6 & 62.4 & 231.2 & 280.3 & 39.0 & 135.9 & 169.9 & 72.2 & 108.9 & 95.1 \\
\hline \multicolumn{16}{|l|}{ Castes } \\
\hline $\mathrm{ST} / \mathrm{SC}$ & 13.1 & 26.1 & 39.1 & 7.9 & 18.1 & 61.5 & 17.9 & 84.1 & 122.0 & 12.3 & 39.3 & 69.9 & 55.0 & 108.6 & 54.0 \\
\hline other backward class & 7.8 & 19.5 & 44.3 & 9.3 & 30.6 & 78.8 & 18.1 & 81.7 & 98.6 & 12.8 & 34.2 & 62.8 & 63.8 & 89.1 & 86.9 \\
\hline other & NA & 23.0 & 46.2 & NA & 39.6 & 106.3 & NA & 95.6 & 131.4 & NA & 43.6 & 85.8 & NA & 82.7 & 67.9 \\
\hline \multicolumn{16}{|l|}{ Religion } \\
\hline Hindu & NA & 21.3 & 46.2 & NA & 30.7 & 79.9 & NA & 79.8 & 108.6 & NA & 36.5 & 73.9 & NA & 88.2 & 69.4 \\
\hline Muslim & NA & 11.7 & 36.4 & NA & 25.3 & 76.4 & NA & 72.3 & 87.0 & NA & 29.4 & 58.8 & NA & 89.3 & 81.8 \\
\hline Christianity & NA & 32.9 & 50.7 & NA & 43.2 & 109.5 & NA & 123.0 & 151.7 & NA & 51.5 & 71.4 & NA & 93.7 & 104.5 \\
\hline others & NA & 0.0 & 27.6 & NA & 0.0 & 177.9 & NA & 0.0 & 0.0 & NA & 0.0 & 27.6 & NA & 0.0 & 177.9 \\
\hline \multicolumn{16}{|l|}{ Marital Status } \\
\hline Never Married & 7.6 & 18.8 & 48.9 & 2.3 & 2.9 & 4.8 & 10.4 & 57.9 & 26.8 & 7.7 & 14.1 & 25.4 & 68.9 & 93.8 & 79.2 \\
\hline Currently Married & 9.8 & 19.6 & 37.5 & 13.5 & 41.4 & 111.0 & 21.2 & 99.4 & 148.2 & 14.1 & 44.6 & 87.0 & 57.0 & 80.4 & 75.9 \\
\hline Widowed/div/separate & 4.5 & 47.6 & 64.5 & 27.3 & 140.7 & 286.4 & 50.3 & 170.4 & 255.5 & 37.0 & 131.9 & 165.2 & 59.0 & 120.1 & 91.8 \\
\hline \multicolumn{16}{|l|}{ Wealth Quintile } \\
\hline poorest & 9.9 & 38.7 & 35.6 & 10.7 & 38.0 & 142.6 & 25.1 & 91.8 & 123.9 & 13.7 & 54.1 & 146.2 & 62.2 & 103.7 & 114.3 \\
\hline poor & 8.1 & 18.5 & 41.9 & 7.9 & 17.6 & 101.5 & 19.5 & 79.4 & 119.0 & 11.8 & 45.3 & 90.1 & 62.7 & 102.8 & 71.4 \\
\hline medium & 11.2 & 17.9 & 59.5 & 6.1 & 21.8 & 63.9 & 15.1 & 81.8 & 93.0 & 13.8 & 40.9 & 62.2 & 68.4 & 93.1 & 88.2 \\
\hline rich & 7.3 & 19.0 & 53.0 & 9.9 & 26.0 & 72.2 & 19.9 & 81.3 & 105.3 & 14.6 & 33.5 & 73.5 & 64.2 & 84.4 & 79.5 \\
\hline richest & 6.5 & 22.5 & 34.4 & 11.4 & 39.9 & 86.9 & 15.6 & 96.8 & 113.3 & 10.1 & 31.1 & 54.8 & 56.9 & 81.0 & 73.0 \\
\hline \multicolumn{16}{|l|}{ NSS Region } \\
\hline Northern region & 7.3 & 11.9 & 38.0 & 3.6 & 21.5 & 55.4 & 11.5 & 51.6 & 73.2 & 11.4 & 22.2 & 54.7 & 49.0 & 73.4 & 66.0 \\
\hline Southern Region & 9.1 & 27.6 & 48.8 & 2.7 & 38.8 & 104.7 & 22.3 & 109.0 & 136.3 & 13.6 & 47.8 & 80.1 & 72.0 & 99.5 & 87.7 \\
\hline Kerala & 8.4 & 21.3 & 44.2 & 9.1 & 31.8 & 83.7 & 18.1 & 85.9 & 109.4 & 12.7 & 37.5 & 69.3 & 62.9 & 89.0 & 78.5 \\
\hline
\end{tabular}

Sources: NSSO Data, 52nd, 60th \& 71st round.

the same time, huge inequalities are seen among poor vs. rich and migrants vs. residents to access the quality of health care check-up. ${ }^{22}$ The major outcome that people in Kottayam, Thrissur, Ernakulam, Alappuzha, and Thiruvananthapuram districts have a maximum reported on CVDs and NCDs hospitalization cases. The concentration of infectious diseases by almost half is found in among under-five children. Among infectious diseases further, hospitalization cases are higher for diarrhea or dysentery. ${ }^{25}$ It is a well-known fact that diarrhea alone accounts for the highest number of deaths among infants followed by acute respiratory infection. ${ }^{8}$ Other infectious diseases with a high percentage of hospitalization are for gastric and peptic ulcers which are found to be higher among young (15-29) and prior elderly groups (45-59) in urban areas. ${ }^{27}$ Furthermore, Tuberculosis also accounts for a high percentage across ages in both the rural and urban areas. Bronchial asthma and abnormality in urination are found to be higher in the category for both children and the elderly. CDs like Jaundice recorded the highest percentage of hospitalization case among infants which are common. Whereas anemia was found to quite prevalent in the adolescent age group, while cancer is found to be on the rise in the middle age, returned migrants and elderly people. ${ }^{28}$

\section{Limitation}

In the respondents with higher socio-economic and educational status because of health consciousness there are chances of over- reporting, but in general this is a risk of under-reporting. Also, there was a change in classification of the types of morbidities from 19952014. ${ }^{8,16}$ Despite these limitations, the morbidity transition and hospitalization issues are useful to understand the present condition of morbidity in Kerala for policy formulation plans on different types of diseases.

\section{Conclusion}

Increasing prevalence of morbidities in Kerala is a major cause of concern. District level morbidities are found to be highest in Kottayam, followed by Thrissur and Kollam. There is need for improvement in health care services and exposure to health issues in the Northern part of Kerala to promote a higher level of consciousness, and health service utilization as in Southern Kerala. ${ }^{5,25}$ There is a need to synchronize specialized health care provision for the elderly at the primary level and a need of great importance for relevant policies aimed at the elderly care. So, it's a need good health care provision, particularly in urban areas, to ensure the early screening and treatment of NCDs and CVDs at primary level which is almost non-existent at present. In the present scenario, as the familial structure is changing and larger numbers of people are living alone (emigrated), the Government needs to focus more on child and elderly health. Also, the chance of being alone and facing poor health will be higher among females and widowed. There is a need for more holistic government programmes that are more 


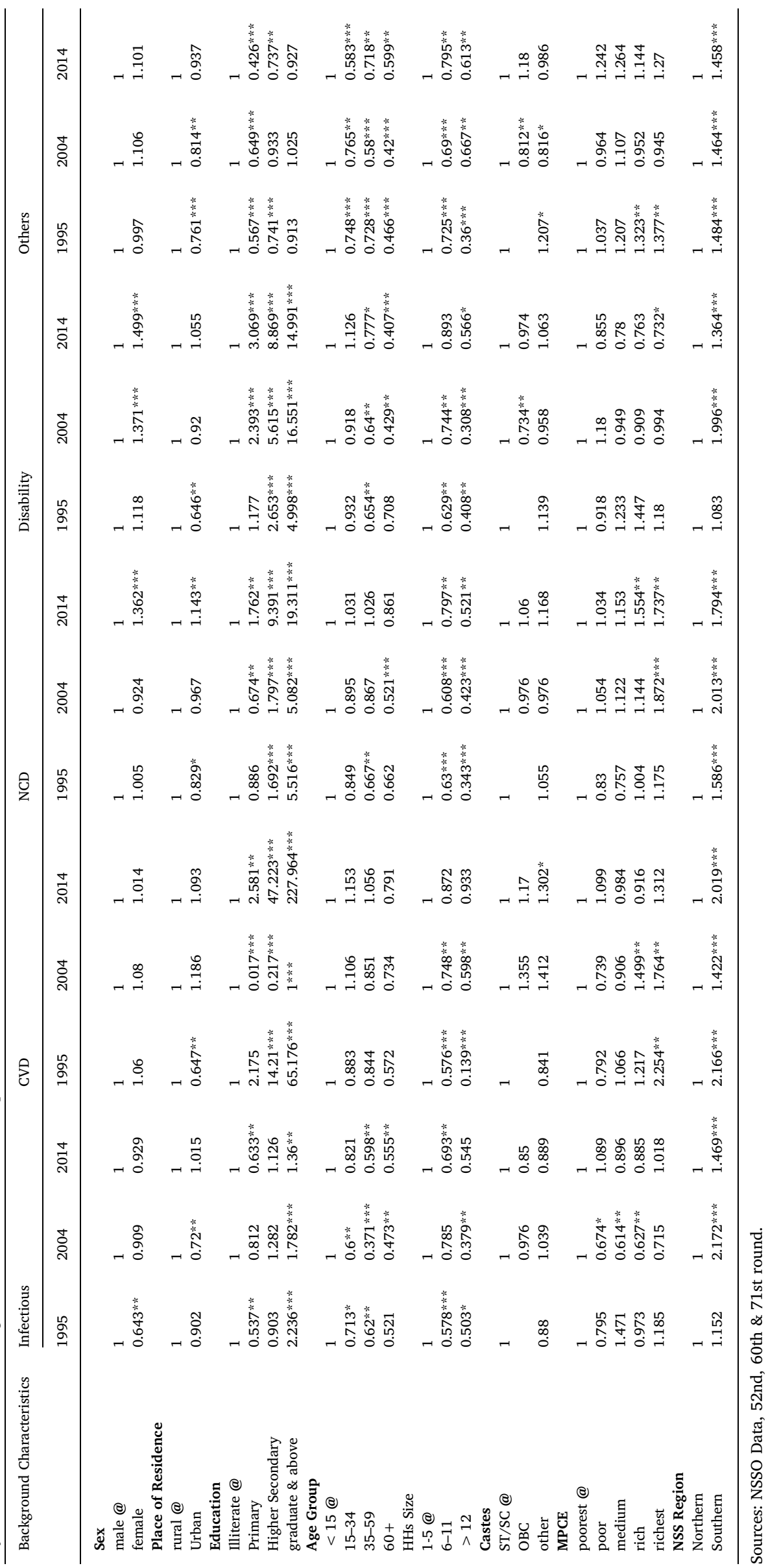


Table 4

Percentage distribution of hospitalised cases by nature of ailment and age groups for Kerala, 2014.

\begin{tabular}{|c|c|c|c|c|c|c|c|c|c|c|c|c|c|c|}
\hline \multirow{3}{*}{$\begin{array}{l}\text { TYPE OF AILMENTS } \\
\text { Place of Residence }\end{array}$} & \multicolumn{14}{|c|}{ HOSPITALIZED } \\
\hline & \multicolumn{2}{|l|}{$0-4$} & \multicolumn{2}{|l|}{$5-14$} & \multicolumn{2}{|c|}{$15-29$} & \multicolumn{2}{|c|}{$30-44$} & \multicolumn{2}{|c|}{$45-59$} & $60+$ & & Total & \\
\hline & $\mathrm{R}$ & $\mathrm{U}$ & $\mathrm{R}$ & $\mathrm{U}$ & $\mathrm{R}$ & $\mathrm{U}$ & $\mathrm{R}$ & $\mathrm{U}$ & $\mathrm{R}$ & $\mathrm{U}$ & $\mathrm{R}$ & $\mathrm{U}$ & $\mathrm{R}$ & $\mathrm{U}$ \\
\hline INFECTIOUS DISEASES & 47.4 & 24.9 & 32 & 28.2 & 11.6 & 16.4 & 24.5 & 17.5 & 19.4 & 22.5 & 27.4 & 13.7 & 21 & 17.9 \\
\hline Fever with loss of consciousness & 2.6 & 3 & 4.7 & 3.2 & 0.3 & 0.2 & 0.7 & 1.4 & 1.5 & 0.8 & 3.6 & 0 & 1.4 & 0.8 \\
\hline Fever with rash/eruptive lesions & 0 & 2 & 0.7 & 0 & 0.3 & 0 & 0.1 & 0 & 0.3 & 0.1 & 0.6 & 0.5 & 0.3 & 0.3 \\
\hline Fever due to DIPHTHERIA, WHOOPING COUGH & 0.7 & 0.6 & 0.6 & 0 & 0.2 & 0 & 0 & 0 & 0.1 & 0 & 0.1 & 0.1 & 0.2 & 0.1 \\
\hline TUBERCULOSIS & 0 & 0 & 0 & 1.2 & 2.9 & 0.3 & 0.4 & 0.4 & 2.3 & 1.1 & 3.9 & 0.3 & 2.1 & 0.5 \\
\hline Filariasis & 0 & 0 & 0 & 0 & 0 & 0 & 0 & 0 & 0 & 0 & 0.2 & 0 & 0 & 0 \\
\hline Tetanus & 0 & 0 & 0 & 0 & 0 & 0 & 0.5 & 0 & 0.2 & 0 & 0 & 0 & 0.1 & 0 \\
\hline HIV/AIDS & 0 & 0 & 0 & 0 & 0 & 0 & 0 & 0 & 0 & 0 & 0 & 0 & 0 & 0 \\
\hline Other sexually transmitted diseases & 0 & 0 & 0 & 0 & 0 & 0 & 0 & 0 & 0 & 0 & 0 & 0 & 0 & 0 \\
\hline Diarrheas/dysentery & 34.1 & 14.2 & 11 & 6 & 2.6 & 2.7 & 8.6 & 5.8 & 4.5 & 2.9 & 6.5 & 4.5 & 7.3 & 4.7 \\
\hline Worms infestation & 0.3 & 0 & 0 & 0 & 0 & 0 & 0 & 0.2 & 0 & 0 & 0 & 0.1 & 0 & 0.1 \\
\hline Discomfort/pain in the eye with redness & 0 & 0 & 0 & 0 & 0 & 0 & 0.1 & 0.1 & 0.2 & 0 & 0.2 & 1.2 & 0.1 & 0.3 \\
\hline Acute upper respiratory infections & 6.6 & 2.7 & 1.8 & 1.4 & 0.1 & 0.6 & 0 & 0.2 & 0.1 & 1.2 & 0.5 & 0.8 & 0.7 & 0.9 \\
\hline Gastric and peptic ulcers & 2.1 & 0.7 & 9.2 & 15.8 & 5.2 & 12.1 & 13.8 & 9.1 & 9.7 & 15.5 & 11.8 & 5.9 & 8.4 & 9.8 \\
\hline Skin infection & 1 & 1.8 & 4.1 & 0.6 & 0.1 & 0.5 & 0.4 & 0.3 & 0.5 & 0.9 & 0.1 & 0.3 & 0.5 & 0.6 \\
\hline CARDIOVASCULAR DISEASES & 2.4 & 1.3 & 0.7 & 0 & 0.4 & 0.7 & 3.5 & 5.5 & 12.3 & 16.4 & 26.2 & 26.1 & 6.3 & 11.1 \\
\hline Stroke/hemiplegia & 0 & 0 & 0 & 0 & 0.1 & 0.1 & 1.9 & 1.9 & 3.3 & 3.3 & 6.2 & 6.2 & 2.6 & 2.6 \\
\hline HYPERTENSION & 0 & 0 & 0 & 0 & 0 & 0.1 & 0.1 & 1.3 & 0 & 1.8 & 0 & 5.5 & 0 & 2 \\
\hline Heart disease & 0 & 1.3 & 0 & 0 & 0.1 & 0.5 & 1.3 & 2.3 & 1.8 & 11.2 & 5.5 & 14.4 & 2 & 6.5 \\
\hline NON-COMMUNICABLE DISEASES & 26 & 59 & 14.4 & 30.5 & 8.9 & 11.1 & 15.4 & 22.1 & 36.3 & 24.4 & 25 & 37.2 & 18.9 & 26.3 \\
\hline Jaundice & 7 & 7 & 0.9 & 0.9 & 0.7 & 0.7 & 1.7 & 1.7 & 1.4 & 1.4 & 0.5 & 0.5 & 1.4 & 1.4 \\
\hline CANCERS & 0 & 0 & 3.5 & 3.5 & 0.1 & 0.1 & 3.9 & 3.9 & 4.1 & 4.1 & 5.2 & 5.2 & 3 & 3 \\
\hline Anaemia (any cause) & 0.5 & 0.5 & 7.1 & 7.1 & 0.5 & 0.5 & 1.1 & 1.1 & 0.2 & 0.2 & 1 & 1 & 0.9 & 0.9 \\
\hline Bleeding disorders & 0 & 0 & 0 & 0 & 0.1 & 0.1 & 0.4 & 0.4 & 0.3 & 0.3 & 0.9 & 0.9 & 0.4 & 0.4 \\
\hline DIABETES & 0 & 0 & 0 & 0 & 0 & 0 & 0 & 0 & 1.3 & 1.3 & 0.7 & 0.7 & 0.4 & 0.4 \\
\hline Under-nutrition & 1.4 & 1.4 & 0 & 0 & 0 & 0 & 0 & 0 & 0 & 0 & 0 & 0 & 0.1 & 0.1 \\
\hline Goitre and other diseases of the thyroid & 0 & 0 & 0 & 0 & 0.1 & 0.1 & 0 & 0 & 0.3 & 0.3 & 0.2 & 0.2 & 0.1 & 0.1 \\
\hline Cholestrol & 0 & 0 & 0 & 0 & 0 & 0 & 0.4 & 0.4 & 0.2 & 0.2 & 0.1 & 0.1 & 0.1 & 0.1 \\
\hline Cataract & 30.4 & 30.4 & 0 & 0 & 0 & 0 & 0.6 & 0.6 & 5.8 & 5.8 & 10.4 & 10.4 & 6 & 6 \\
\hline GLAUCOMA & 0 & 0 & 0 & 0 & 0 & 0 & 0 & 0 & 0.3 & 0.3 & 0.2 & 0.2 & 0.1 & 0.1 \\
\hline Earache with discharge & 0 & 0 & 2.5 & 2.5 & 0 & 0 & 0.6 & 0.6 & 0 & 0 & 0 & 0 & 0.2 & 0.2 \\
\hline Cough with sputum with & 1.1 & 1.1 & 0 & 0 & 0.7 & 0.7 & 0.4 & 0.4 & 1.1 & 1.1 & 0.8 & 0.8 & 0.8 & 0.8 \\
\hline Bronchial asthma & 6.1 & 6.1 & 9.3 & 9.3 & 2 & 2 & 2.1 & 2.1 & 2.2 & 2.2 & 11.5 & 11.5 & 5.1 & 5.1 \\
\hline Any difficulty or abnormality in urination & 2.5 & 2.5 & 6.3 & 6.3 & 0.3 & 0.3 & 3.7 & 3.7 & 4.9 & 4.9 & 5.1 & 5.1 & 3.4 & 3.4 \\
\hline Pelvic region/reproductive tract infection & 0 & 0 & 0.9 & 0.9 & 0.7 & 0.7 & 2.3 & 2.3 & 0.9 & 0.9 & 0.5 & 0.5 & 1 & 1 \\
\hline Change/irregularity in menstrual cycle & 0 & 0 & 0 & 0 & 1.5 & 1.5 & 3.6 & 3.6 & 1.3 & 1.3 & 0.3 & 0.3 & 1.4 & 1.4 \\
\hline Pregnancy with complications before or during labour & 0 & 0 & 0 & 0 & 4 & 4 & 1.3 & 1.3 & 0 & 0 & 0 & 0 & 1.3 & 1.3 \\
\hline Complications in mother after birth of child & 0 & 0 & 0 & 0 & 0.4 & 0.4 & 0 & 0 & 0 & 0 & 0 & 0 & 0.1 & 0.1 \\
\hline Illness in the newborn/sick newborn & 10 & 10 & 0 & 0 & 0 & 0 & 0 & 0 & 0 & 0 & 0 & 0 & 0.7 & 0.7 \\
\hline DISABLITY & 12.2 & 4.2 & 32.8 & 21.5 & 10.2 & 6.3 & 21 & 22.3 & 13.9 & 21.9 & 11 & 13.5 & 14.4 & 14.4 \\
\hline Mental retardation & 0 & 0 & 0 & 0 & 0 & 0 & 0 & 0 & 0 & 0 & 0.3 & 0.3 & 0.1 & 0.1 \\
\hline Mental disorders & 0 & 0 & 0 & 0 & 0.6 & 0.6 & 11.1 & 11.1 & 0.5 & 0.5 & 0.2 & 0.2 & 2.4 & 2.4 \\
\hline Headache & 0 & 0 & 0 & 0 & 0.1 & 0.1 & 0.6 & 0.6 & 0.4 & 0.4 & 0 & 0 & 0.2 & 0.2 \\
\hline Seizures or known epilepsy & 0 & 0 & 2.9 & 2.9 & 0.7 & 0.7 & 0 & 0 & 0.4 & 0.4 & 0 & 0 & 0.3 & 0.3 \\
\hline Weakness in limb muscles and difficulty in movements & 0.7 & 0.7 & 0 & 0 & 0.3 & 0.3 & 0.2 & 0.2 & 0.7 & 0.7 & 0.8 & 0.8 & 0.5 & 0.5 \\
\hline Others including Impaired cognition, memory loss & 0 & 0 & 0 & 0 & 0 & 0 & 0.5 & 0.5 & 0.4 & 0.4 & 0.9 & 0.9 & 0.4 & 0.4 \\
\hline Decreased vision (chronic) & 0 & 0 & 0 & 0 & 0 & 0 & 0 & 0 & 0.2 & 0.2 & 0 & 0 & 0 & 0 \\
\hline Others (eye movements - strabismus and adnexa) & 0 & 0 & 0 & 0 & 0.2 & 0.2 & 0.1 & 0.1 & 0.3 & 0.3 & 0.4 & 0.4 & 0.2 & 0.2 \\
\hline Decreased hearing or loss of hearing & 0 & 0 & 0 & 0 & 0 & 0 & 0.1 & 0.1 & 0 & 0 & 0 & 0 & 0 & 0 \\
\hline Diseases of mouth/teeth/gums & 0 & 0 & 0 & 0 & 0.2 & 0.2 & 0 & 0 & 0.5 & 0.5 & 0 & 0 & 0.1 & 0.1 \\
\hline Joint or bone disease & 2.7 & 2.7 & 2 & 2 & 0.2 & 0.2 & 1 & 1 & 3.1 & 3.1 & 4.3 & 4.3 & 2.2 & 2.2 \\
\hline Back or body aches & 0 & 0 & 0 & 0 & 0 & 0 & 0.1 & 0.1 & 0.4 & 0.4 & 0 & 0 & 0.1 & 0.1 \\
\hline Accidental injury, road traffic accidents and falls & 0.4 & 0.4 & 14.4 & 14.4 & 2.9 & 2.9 & 8.2 & 8.2 & 14 & 14 & 6.3 & 6.3 & 7 & 7 \\
\hline Accidental drowning and submersion & 0 & 0 & 0 & 0 & 0 & 0 & 0 & 0 & 0 & 0 & 0 & 0 & 0 & 0 \\
\hline Burns and corrosions & 0 & 0 & 0 & 0 & 0.6 & 0.6 & 0.1 & 0.1 & 0.7 & 0.7 & 0.2 & 0.2 & 0.3 & 0.3 \\
\hline Poisoning & 0.5 & 0.5 & 1.9 & 1.9 & 0.5 & 0.5 & 0.3 & 0.3 & 0.3 & 0.3 & 0 & 0 & 0.3 & 0.3 \\
\hline Intentional self-harm & 0 & 0 & 0 & 0 & 0 & 0 & 0 & 0 & 0 & 0 & 0 & 0 & 0 & 0 \\
\hline Assault & 0 & 0 & 0.3 & 0.3 & 0 & 0 & 0.1 & 0.1 & 0.3 & 0.3 & 0.2 & 0.2 & 0.1 & 0.1 \\
\hline OTHERS & 12 & 10.5 & 20 & 19.8 & 69 & 65.6 & 35.7 & 32.7 & 18.3 & 14.9 & 10.4 & 9.5 & 39.5 & 30.3 \\
\hline All other fevers (Includes malaria, typhoid) & 8.2 & 7.8 & 9.8 & 15.3 & 3.2 & 3.7 & 2.5 & 4.7 & 2.9 & 5.1 & 2.5 & 4.3 & 3.4 & 5.2 \\
\hline Lump or fluid in abdomen or scrotum & 1 & 1 & 8.9 & 8.9 & 2 & 2 & 2.6 & 2.6 & 3.7 & 3.7 & 1.4 & 1.4 & 2.4 & 2.4 \\
\hline Gastrointestinal bleeding & 0 & 0 & 0 & 0 & 0.7 & 0.7 & 2.3 & 2.3 & 0.5 & 0.5 & 1 & 1 & 1 & 1 \\
\hline Contact with venomous & 0 & 0 & 0 & 0 & 0.1 & 0.1 & 0.7 & 0.7 & 0 & 0 & 0.2 & 0.2 & 0.2 & 0.2 \\
\hline Symptom not fitting into any of above categories & 1.3 & 1.3 & 1.2 & 1.2 & 1.4 & 1.4 & 3.4 & 3.4 & 7.8 & 7.8 & 3.5 & 3.5 & 3.5 & 3.5 \\
\hline Could not even state the main symptom & 0 & 0 & 0 & 0 & 0 & 0 & 0.2 & 0.2 & 0 & 0 & 0.9 & 0.9 & 0.3 & 0.3 \\
\hline Other & 0 & 0 & 0 & 0 & 58.3 & 58.3 & 21 & 21 & 0 & 0 & 0 & 0 & 19.6 & 19.6 \\
\hline
\end{tabular}

Source: NSSO Data, 71st round, 2014. 
inclusive towards free health facilitate in India. ${ }^{7}$

\section{Consent for publication}

Not applicable.

\section{Conflict's interests}

The authors declare that they have no conflict's interests.

\section{Funding}

This research did not receive any specific grant from funding agencies in the public, commercial, or not-for-profit sectors.

\section{Authors contributions}

Conceived and designed the experiments: KP. Performed the experiments: KP. Analysed the data: KP. Contributed reagents/materials/ analysis tools: KP and RC. Wrote the paper: MC KP RC and RS.

\section{Availability of data and material}

The dataset is available in the public domain at the Ministry of Statistics and Program Implementation, Government of India website.

\section{List of Abbreviations}

$\begin{array}{ll}\text { NCDs } & \text { Non Communicable Diseases } \\ \text { CVDs } & \text { Cardio Vascular Diseases } \\ \text { NSSO } & \text { National Sample Survey Organization } \\ \text { RGI } & \text { Registrar General of India } \\ \text { GOI } & \text { Government of India } \\ \text { ICD } & \text { International Classification of Disease } \\ \text { MPCE } & \text { Monthly per Capita Expenditure } \\ \text { ST } & \text { Scheduled Tribe } \\ \text { SC } & \text { Scheduled Caste } \\ \text { WHO } & \text { World Health Organization }\end{array}$

\section{Appendix A. Supplementary data}

Supplementary data to this article can be found online at https:// doi.org/10.1016/j.cegh.2019.03.011.

\section{References}

1. Parayil G, ed. Kerala: The Development Experience: Reflections on Sustainability and
Replicability. Zed Books; 2000 Aug 12.

2. NSSO. Morbidity and Treatment of Ailments New Delhi: Ministry of Statistics and Programme Implementation, Government of India; 1998 Report no. 441.

3. NSSO. Morbidity Health Care and the Condition of Aged New Delhi: Ministry of Statistics and Programme Implementation, Government of India; 2006 Report no. 507.

4. NSSO. India Social Consumption and Health New Delhi: Ministry of Statistics and Programme Implementation, Government of India; 2015 Report no. 574.

5. Murray CJ, Chen LC. Understanding morbidity change. Popul Dev Rev. 1992 Sep 1:481-503.

6. Panikar PG, Soman CR. Health Status of Kerala: The Paradox of Economic Backwardness and Health Development. InHealth Status of Kerala: the Paradox of Economic Backwardness and Health Development. Centre for Development Studies; 1984.

7. Kumar BG. Low mortality and high morbidity in Kerala reconsidered. Popul Dev Rev. 1993 Mar 1:103-121.

8. Paul K, Singh J. Emerging trends and patterns of self-reported morbidity in India: evidence from three rounds of national sample survey. J Health Popul Nutr. 2017 Dec;36(1):32.

9. Kannan KP. Health and Development in Rural Kerala: A Study of the Linkages between Socioeconomic Status and Health Status. Integrated Rural Technology Centre of the Kerala Sastra Sahitya Parishad; 1991.

10. Gumber A, Berman P. Measurement and pattern of morbidity and the utilization of health services: some emerging issues from recent health interview surveys in India. $J$ Health Popul Dev Ctries. 1997;1(1):16-43.

11. Dilip TR. Understanding levels of morbidity and hospitalization in Kerala, India. Bull World Health Organ. 2002;80:746-751.

12. Sinimole KR. Emerging patterns of morbidity and hospitalization-a comparison of Kerala and Bihar. Illn Crisis Loss. 2017 Nov 281054137317744249.

14. Duraisamy P. Morbidity in Tamil Nadu: levels, differentials and determinants. Econ Pol Wkly. 1998 Apr 25:982-990.

15. Agrawal G, Arokiasamy P. Morbidity prevalence and health care utilization among older adults in India. J Appl Gerontol. 2010 Apr;29(2):155-179.

16. Ghosh S, Arokiasamy P. Emerging patterns of reported morbidity and hospitalisation in West Bengal, India. Glob Public Health. 2010 Jul 1;5(4):427-440.

17. Goyal A, Yusuf S. The burden of cardiovascular disease in the Indian subcontinent. Indian J Med Res. 2006 Sep 1;124(3):235-244.

18. Anand E, Singh J. Hypertension stages and their associated risk factors among adult women in India. J Popul Soc Stud. 2017 Jan;25:42-54.

19. Bhise MD, Patra S. Prevalence and correlates of hypertension in Maharashtra, India: a multilevel analysis. PLoS One. 2018 Feb 5;13(2):e0191948.

20. Dilip TR. Age-specific analysis of reported morbidity in Kerala, India. World Health Popul. 2007 Dec 15;9(4).

21. Dilip TR. Utilization of inpatient care from private hospitals: trends emerging from Kerala, India. Health Policy Plan. 2010 Mar 27;25(5):437-446.

22. Zachariah KC, Mathew ET, Rajan SI. Dynamics of Migration in Kerala: Dimensions, Differentials, and Consequences. Orient Blackswan; 2003.

23. Blacker CP. Stages in population growth. Eugen Rev. 1947 Oct;39(3):88.

25. Dilip TR. The burden of ill health among elderly in Kerala. HelpAge India-Res Dev J. 2001;7(2):7-15.

26. Kutty VR. Historical analysis of the development of health care facilities in Kerala State, India. Health Policy Plan. 2000 Mar 1;15(1):103-109.

27. Das B, Sengupta R, Paul K. Regional variation and determinants of well-being of the elderly in India. J Popul Soc Stud [JPSS]. 2018 Jul 13;26(3):219-234.

28. Purty AJ, Bazroy J, Kar M, Vasudevan K, Zacharia P, Panda P. Morbidity pattern among the elderly population in the rural area of Tamil Nadu, India. Turk J Med Sci 2006 Feb 27;36(1):45-50.

29. ORGI. Primary Census Abstract. Office of the Registrar General and Census Commisoners, India. New Delhi: Ministry of Home Affairs, Government of India; 2011.

30. WHO. International Classification Disease-10. Geneva: World Health Organization; 2012 